\title{
Interview with Marcos Von Sperling
}

\author{
Paulo Ricardo Frade ${ }^{1}$
}

${ }^{1}$ Centro Universitário de Formiga (UNIFOR-MG)

We interviewed the Full Professor of the Department of Sanitary and Environmental Engineering of UFMG; Researcher at CNPq (level 1A) and PhD in Environmental Engineering from Imperial College - London, England, Dr. Marcos Von Sperling.

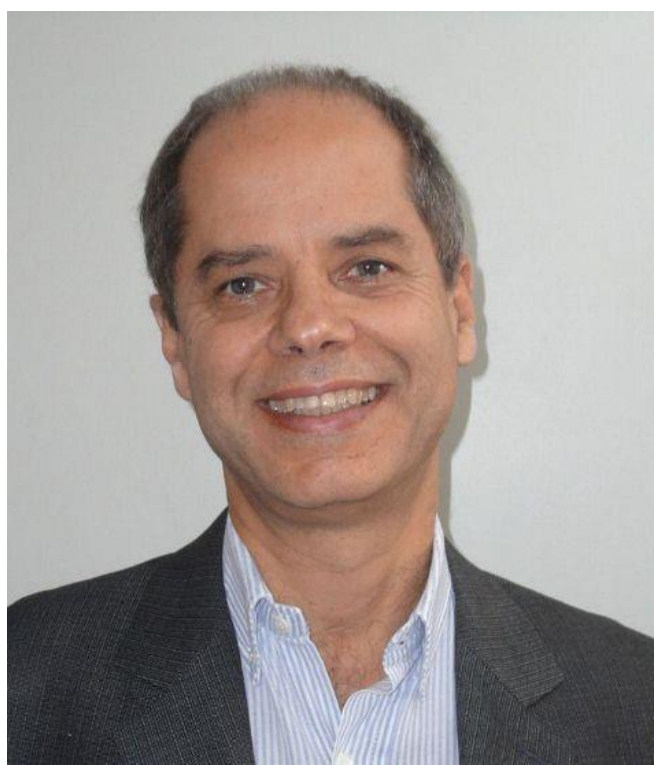

Dr. Marcos Von Sperling is Professor of the Department of Sanitary and Environmental Engineering at UFMG. Researcher at CNPq (level 1A). PhD in Environmental Engineering from Imperial College - London, England, 1990; Master in Sanitary Engineering, Federal University of Minas Gerais - UFMG, 1983; Postgraduate in Sanitary Engineering from IHE Delft Institute for Water Education, The Netherlands, 1981; and Graduation in Civil Engineering by UFMG, 1979.

Fellow of the International Water Association (IWA). Coordinator of the IWA Specialist Group on Wastewater Pond Technology (2009-2013). Editor of the IWA International Journal - Journal of Water Sanitation and Hygiene for Development (as of 2010). Coordinator of the environmental engineering advisory committee of $\mathrm{CNPq}$ (2007-2008) and member of the advisory committees of CNPq (2005-2007, 20162019) and Capes (2005-2007).

Visiting Professor at Unesco-IHE, Delft, Netherlands (from 2013). Participation in more than 200 academic and master's degrees. Advisor of about 50 students of scientific initiation, 43 of master's and 14 of doctorate. Author of several textbooks published in Portuguese, English and Spanish and more than 100 scientific papers in periodicals and 200 works in annals of events in the areas of water pollution and sewage treatment. It received the receipt of thirteen national awards / distinctions and four international awards / distinctions.

In 2017 he received the title of International Honorary Member of the American Academy of Environmental Engineers and Scientists. He is the first Brazilian chosen by the council of trustees of the entity, based in the United States, to integrate the academy. 
1) In your opinion, what is the main challenge for scientific research and production in Brazil?

There are several challenges faced by researchers. The first one that comes to everyone's mind relates to the current scenario of financial constraints, where the fundings for research, including scholarships, sponsoring and capital, has been reduced. There is also the challenge of maintaining the equipment purchased, whose operating and maintenance costs are usually very high. Another difficulty faced by universities relates to the difficulty of allocating laboratory technicians: the retirement or departure of technicians has not been restored in equal numbers. There is also bureaucracy involved in the financial management of research projects. In short, there are several difficulties that a researcher must face and overcome. Fortunately, what we see in our area is a great dedication of the researchers, who have not measured their efforts to overcome these obstacles and contribute to the scientific and technological development of the country.

Talking about the scientific production, publishing is not easy, especially in high-level journals. But publishing is a learning exercise for both young researchers and mature researchers. Having a rejected article or several suggestions for review should not act as a disincentive, but as a chance for reflection and a search for humility, which are fundamental requirements for a researcher. We always have a lot to learn, and getting feedback from others can help our growth. Another subject I would like to add is that publishing should be a pleasure, not an obligation. We should not simply publish to improve productivity statistics in our personal curriculum or graduate program, but rather because it is important to make public what we have developed and discovered, and thus help in the advancement of the industry.

2) From your experience, what makes an institution stand out for its scientific research? Would you have a hint of a rising field in your area for fresh students who want to join in academic life?

Surveys can be of a basic or applied nature, and both are important. In my work field, I usually deal with applied research, and I believe that the success of these researches is associated to the possibility of application in real scale, helping to solve existing problems and enabling a development that guarantees the health of the population and the salubrity of the environment. A metric widely used to verify the degree of prominence of research carried out by an institution relates to publications, both in quantity and quality. But we must also analyze that this isn't enough yet, and the research must effectively contribute to the development of our country and other regions with similar demands. As there is no satisfactory metric for this goal, it ends up not being taken into account in several evaluations. We can not forget that a successful research is also supported by the opportunity of development of the group involved, highlighting students of scientific initiation, mastering and doctorate degrees. The research does not end with the developed product or the publication achieved, but is multiplied by the various agents who participated in it, who will be able to address other topics in the future, and expand the scope of the research developed in our country.

3) What are the characteristics that a young student should increase for the development of relevant research? Which ones do you consider most important to become a member of your research group?

Dedication, commitment, interest, curiosity, initiative and ability to work in groups are desired characteristics for a researcher. But it is essential to have pleasure in working with the researched topic. Pleasure expands several of these features and greatly increases our productivity.

4) Do you think that the research in the field of basic sanitation in Brazil has been relatively incipient?

I think we have researched a lot about basic sanitation in Brazil and achieved important results. In most industries we have technologies developed or well adapted to our conditions, and we are no longer importers of technological solutions from more developed countries. We must be proud of our scope, although we still have much to do in order to these goals are reflected in adequate coverage of sanitation services in the country, both in the urban and rural areas. A good example of cooperative network research, involving universities and sanitation service providers in the country, working on common themes with aligned objectives was the PROSAB (Basic Sanitation Research Program). It has been a milestone in recent research history in the country, and has generated solutions that are effectively being implemented in the four areas of basic sanitation (water supply, sewage, solid waste management and rainwater management).

5) What are the main difficulties arising from the lack of sewage treatment? What do you think that deserves further academic research on this field?

The lack of sewage treatment, which is associated with more than half of our population, leads to widely known environmental problems. But we have to remember that even where there is sewage treatment, it may be inadequate or insufficient. So we do not only have to deploy new treatment plants where there isn't any, but also ensure that existing stations do their job well. This is a great challenge that stands before us. But where there are challenges there are opportunities, and this can be a great field of work for our future professionals. 
In relation to new academic investigations in this field, the area of treatment of sewage is wide enough to shelter researchers of different formations. It is impressive the accumulated knowledge that already exists about biochemistry, microbiology, hydrodynamics, mathematical modeling and other areas associated with sewage treatment, but more impressive still is to see how much we can still discover and move forward. There is space in all areas, and this scenario will continue for decades and decades.

6) Patterns are changing over time, growing urbanization and climate change potentially increase the risk of floods, droughts and storms. How can these changes affect the capacity and operations of existing water and sanitation services?

The changes most easily perceived by the population have been the extensions of the extremes of floods and droughts. But these have also occurred due to anthropogenic interventions in river basins that exceed their own carrying capacity. We have to train ourselves on issues associated with climate change, but we also have to do our basic homework to ensure green areas in the basin, reduce waterproofing, protect springs and riparian forests, and treat sewage. All this is already widely known, but the pressure to grow and occupy, in most cases, uncontrolled, has unfortunately been stronger.

7) What is the role and importance of the sanitation plan as a management tool? How can this topic be treated academically?

Planning is essential. We have often seen the implementation of solutions within a closed optics, which covers only one point within the broad sphere of sanitation. Solutions that are implemented due to pressures or conveniences. Solutions that do not see the full interaction between the four main axes of sanitation. Solutions that do not evaluate well the resulting environmental benefits, or that do not take into account the urban and rural population's wishes. Sanitation plans should seek this integrated vision, so that, in the end, the benefits are actually achieved, and that they are sustainable. The academy can cover several of these points in its research, grounded in the fact that sanitation solutions are not merely technological but involve various fields of knowledge.

8) How does the lack of basic sanitation in Brazil reflect and accentuate social inequality? How can the academic universe collaborate to alleviate this problem?

Lack of sanitation and social inequality are intertwined. Places with lower HDI are usually sites with low sanitation infrastructure. Places with low sanitation infrastructure are associated with a poor, unhealthy population with a poor quality of life. The academic universe can contribute by forming good graduate and postgraduate students who are competent and committed professionals, and who can effectively contribute to the sector. The academy can also provide training and training courses for professionals at other levels. You can also conduct research that effectively catalyzes our development. In addition, it can form opinions and position itself in the defense of essential values and principles.

9) One of the factors contributing to the mismanagement of water resources in the country is the non-treatment of sewage. When it comes to suggesting the reuse of treated water, what practices have already been implemented in this sense and how can we proceed to increase the reuse?

The reuse of water (use of treated sewage) has already been researched, both on the land level and on a wider scale, of a sewage treatment plant in a community. At the property level, the segregation of the effluents generated in the residence has been studied, with subsequent treatment of each one of the lines and separate reutilization, in the residence, building or condominium. The industry dosen't takes actions at the end of the line (treatment plant) anymore, but seeks to reduce the generation of effluents, to recycle, to reuse. Urban sewage treatment plants still practice the use of treated effluents in agriculture, industry and the urban environment. In Brazil, we are in the process of regulating the practices of this reuse, and it is hoped that it can be expanded, from the advent of the legal framework. Technology exists, and it is necessary to advance in the issues of management, regulation and perception of the population.

10) Send an encouraging message to our young readers who are interested in starting their academic life based on your successful career.

Work with pleasure, and give your best! Opportunities will appear and you will be able to take advantage of them!

Thank you for your support, attention and collaboration for the publication of the Journal, on behalf of UNIFOR / MG (Centro Universitário de Formiga / MG) and Conexão Ciência.

Prof. Paulo Ricardo Frade. 